\title{
Author Correction: Radionuclides from the Fukushima Daiichi Nuclear Power Plant in terrestrial systems
}

Yuichi Onda (D), Keisuke Taniguchi, Kazuya Yoshimura®D, Hiroaki Kato, Junko Takahashi, Yoshifumi Wakiyama, Frederic Coppin and Hugh Smith (1)

Nature Reviews Earth \& Environment (2020) https://doi.org/10.1038/s43017-020-0099-x Published online 27 Oct 2020

In the originally published article, the values along the mass depth axes in Figure $4 \mathrm{a}$ and $4 \mathrm{~b}$ were slightly misaligned, and the relaxation mass depth markers shown in Figure $4 \mathrm{~b}$ and $4 \mathrm{c}$ incorrectly located. Both have been corrected in the HTML and PDF versions of the article.

https://doi.org/10.1038/s43017-020-00119-7 I Published online 11 November 2020

(๑) Springer Nature Limited 2020 